\title{
Structural and functional validation of Microsystin synthetases
}

\author{
Swapnil G. Sanmukh and Waman N. Paunikar* \\ *Corresponding Author: Applied Aquatic Ecosystem Division, National Environmental Engineering Research Institute (NEERI), \\ Nagpur-440020, Maharashtra, India. Telephone: 0712-2249885-9, Fax: 0712-2249762, \\ E-mail:wn_paunikar@neeri.res.in.
}

\begin{abstract}
The structure and function prediction for the Microsystin synthetases from Microsystis aerogenosa (LNSAMB) were carried out for verifying the authenticity of the sequenced genes. The genes for Microsystin synthetases (mcyA, $m c y B$, $m c y D$ and $m c y E$,), were predicted by the application of computational methods and Bioinformatics web tools. The probable function prediction for the proteins was done by using Bioinformatics web tools like CDD-BLAST, INTERPROSCAN, PFAM and COGs by searching protein databases for the presence of conserved domains. While tertiary structures were constructed using PS $^{2}$ Server- Protein Structure Prediction server. This study revealed structural and functional validation of sequenced genes.
\end{abstract}

Keywords- sequenced genes; Bioinformatics web tools, conserved domains, Protein structure prediction and validation.

\section{INTRODUCTION}

The biosynthesis of microcystin has been elucidated for two strains of Microcystis aeruginosa [11, 12, 16]. Microcystin is synthesized nonribosomally via a giant enzyme complex comprising peptide synthetases, polyketide synthases (PKSs),

and additional modifying enzymes. Nonribosomal peptide Synthetases (NRPSs), which catalyze the formation of peptides by a thiotemplate mechanism, are found in both prokaryotes and lower eukaryotes. Genetic diversity with respect to microcystin production in natural populations has only been investigated in the genus Microcystis. In natural Microcystis populations, the simultaneous presence of various mcy genotypes and nonmcy genotypes has been found [9]. It has only become possible very recently to relate the genotype of a potential microcystin producer to its phenotype (microcystin synthesis), thus allowing one to prove the traditional assumption that microcystin producing strains should represent specific genotypes that differ genetically from non-microcystin producing strains by containing the $m c y$ genes [6]. Interestingly, a number of Microcystis strains have been shown to contain $m c y$, but lack detectable microcystins $[8,10,12,16]$. The reason why those strains do not synthesize microcystins is unclear, but it has been speculated that mutations within the mcy gene cluster might 
have occurred during cultivation [8]. Whether or not those inactive microcystin genotypes also occur under natural conditions is unknown.

The in-silico studies of Microsystin synthetases genes for identifying their structure and function is an attempt to understand their authenticity and validation in Microsystis aerogenosa (LNSAMB). Bioinformatics web tools like CDD-BLAST, INTERPROSCAN, PFAM and COGs can search the orthologous sequence in biological sequence databases for the target sequence and assist in the categorizing protein into specific family [7]. The online automated servers are available which can predict the three dimensional structures by using the strategy of aligning target sequences with orthologous sequences by virtue of sequence homology using best scored template of orthologous family member. Here, we have predicted 3-D structure using Protein Structure Prediction Server $\left(\mathrm{PS}^{2}\right.$ server) $[5,18]$.

\section{MATERIALS AND METHODS}

\section{A. Sequence Retrieval}

The Complete gene sequences for 4 microcystin synthetases were downloaded from the Genebank (http://www.ncbi.nlm.nih.gov/nuccore/? term=sangolkar).

\section{B. Functional Annotations}

The screening of the sequenced genes for the presence of conserved domains using the web-tools were carried out by using bioinformatics web tools like

CDD-BLAST

(http://www.ncbi.nlm.nih.gov/BLAST/) [2; 3, 14], INTERPROSCAN（http://www.abi.ac.uk/interpro) [18], Pfam (http://www.pfam.sanger.ac.uk/) [1] and COGs (http://www.ncbi.nih.gov/cog) [13] were used, which shows the ability to search the defined conserved domains in the sequences and assist in the classification of proteins in appropriate family.

\section{Functional Categorization}

The function prediction web tools have shown variable results depending upon the information available in databases, when searched for the conserved domains in gene sequences.

\section{Protein Structure Prediction}

Online PS ${ }^{2}$ Protein Structure Prediction Server was used to generate 3D-structures of isolated protein gene (http://www.ps2.life.nctu.edu.tw/) [2, 4, 5, 14, 17]. The server accepts the protein (query) sequences in FASTA format and uses the strategies of Pair-wise and multiple alignments to generate resultant proteins 3D structures, Which are constructed using structural positioning information of atomic coordinates for known template in PDB format using best scored 
alignment data. Where the selection of template was based on the same conserved domain detected in the functional annotations and which must be available in the structure alignment for modeling purpose.

\section{RESULTS AND DISCUSSION}

The in silico structure and function validation of the four microcystin synthetase genes were done. The proteins were classified by using sequence similarity search with close orthologous family members available in various protein databases using the web tools. The predictions of 3-D structures of protein were done by using online automated $\mathrm{PS}^{2}$ server. The analysis of proteins of Microsystis aerogenosa (LNSAMB) for function annotations was done by using web tools for their classification into particular enzymatic family based on conserved domain available in the sequence which are represented in respective Table 1 . The $(\mathrm{PS})^{2}$ Server built the three dimensional structures for all 4 proteins satisfactorily using best scored orthologous template which are represented in fig. 1 through 4 . The templates with best scoring with protein sequences are represented in the order as Template ID, Identity, Score and Evalue which represented in structure column.

TABLE I Structure And Function PREDICTIONS For Microcystin SyNTHETASE genes

\begin{tabular}{|c|c|c|c|c|c|}
\hline Accession No. & CDD-BLAST & Interproscan & Pfam & Cogs & $\mathrm{PS}^{2}$ Structure \\
\hline AED87020.1 & $\begin{array}{l}\text { Acetyl-CoA Synthetaseand similar } \\
\text { proteins; This superfamily contains the } \\
\text { adenylation domains of firefly } \\
\text { luciferases, long chain fatty acid CoA } \\
\text { ligases, nonribosomal peptide } \\
\text { synthetases, acyl-CoA ligases, and other } \\
\text { acyl-adenylate/thioester forming } \\
\text { enzymes. This domain catalyzes the } \\
\text { formation of substrate-CoA in a two-step } \\
\text { reaction: the formation of substrate-AMP } \\
\text { through ATP hydrolysis as an } \\
\text { intermediate, followed by the formation } \\
\text { of substrate-CoA and the release of } \\
\text { AMP. }\end{array}$ & $\begin{array}{l}\text { AMP-dependent } \\
\text { synthetase/ligase }\end{array}$ & $\begin{array}{l}\text { AMP-binding } \\
\text { enzyme }\end{array}$ & $\begin{array}{l}\text { Non-ribosomal } \\
\text { peptide synthetase } \\
\text { modules and related } \\
\text { proteins }\end{array}$ & 1amuA- $38-100-8 \mathrm{e}-23$ \\
\hline AED87019.1 & $\begin{array}{l}\text { Rossmann-fold NAD }(\mathrm{P})(+) \text {-binding } \\
\text { proteins; A large family of proteins that } \\
\text { share a Rossmann-fold } \\
\mathrm{NAD}(\mathrm{P}) \mathrm{H} / \mathrm{NAD}(\mathrm{P})(+) \text { binding (NADB) } \\
\text { domain. The NADB domain is found in } \\
\text { numerous dehydrogenases of metabolic } \\
\text { pathways such as glycolysis, and many } \\
\text { other redox enzymes. NAD binding } \\
\text { involves numerous hydrogen-bonds and } \\
\text { van der Waals contacts, in particular H- } \\
\text { bonding of residues in a turn between the } \\
\text { first strand and the subsequent helix of } \\
\text { the Rossmann-fold topology. }\end{array}$ & $\begin{array}{l}\text { Beta-ketoacyl synthase; } \\
\text { Polyketide synthase, KR } \\
\text { and NAD(P)-binding } \\
\text { domain }\end{array}$ & KR domain & $\begin{array}{l}\text { Polyketide synthase } \\
\text { modules and related } \\
\text { proteins }\end{array}$ & $2 \mathrm{fr} 1 \mathrm{~A}-35-80-1 \mathrm{e}-16$ \\
\hline
\end{tabular}


Characteristically, this turn exhibits a consensus binding pattern similar to GXGXXG, in which the first 2 glycines participate in $\mathrm{NAD}(\mathrm{P})$-binding, and the third facilitates close packing of the helix to the beta-strand. Typically, proteins in this family contain a second domain in addition to the NADB domain, which is responsible for specifically binding a substrate and catalyzing a particular enzymatic reaction.

AED87018.1 Phosphopantetheine attachment site; A 4'-phosphopantetheine prosthetic group is attached through a serine. This prosthetic group acts as a 'swinging arm' for the attachment of activated fatty acid and amino-acid groups. This domain forms a four helix bundle. This family includes members not included in Prosite. The inclusion of these members is supported by sequence analysis and functional evidence. The related domain of Listonella angillarum AngR has the attachment serine replaced by an alanine.

AED87017.1 Non-ribosomal peptide synthetase modules and related proteins [Secondary metabolites biosynthesis, transport, and catabolism]
Phosphopantetheinebinding and Acyl carrier protein-like

Condensation domain $\begin{aligned} & \text { Condensation } \\ & \text { domain }\end{aligned}$

Phosphopanteth eine attachment site prot

-

Non-ribosomal peptide synthetase modules and related proteins
2jgpA- 36- 110- 5e-26

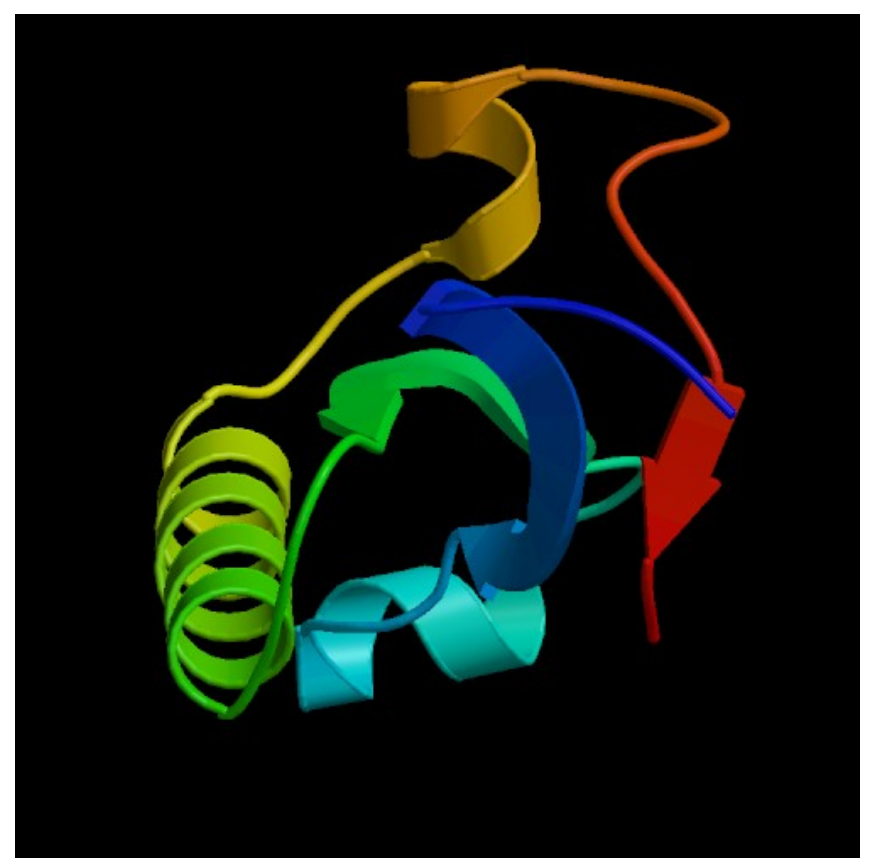

Fig 1. Genebank Accession No. AED87017.1 


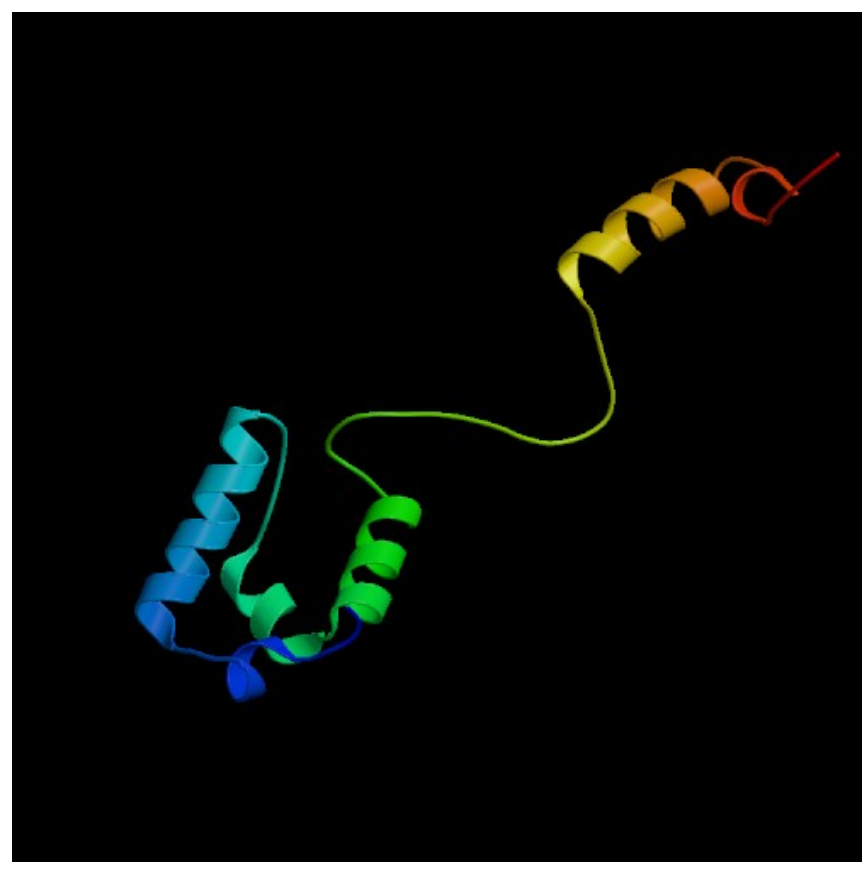

Fig 2. Genebank Accession No. AED87018.1

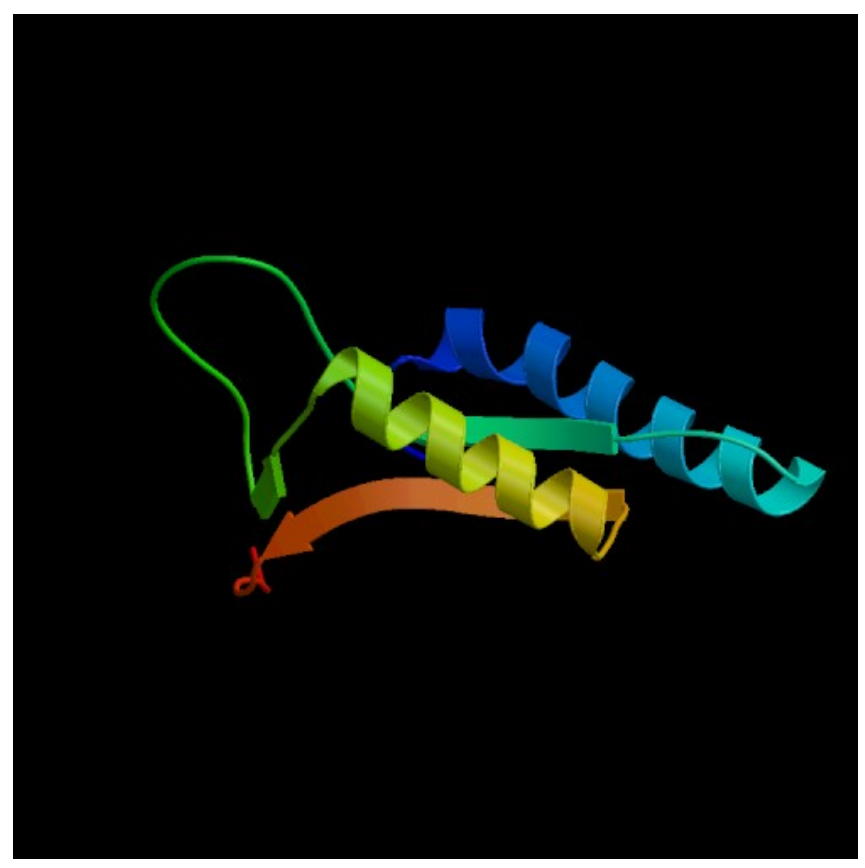

Fig 3. Genebank Accession No. AED87019.1 


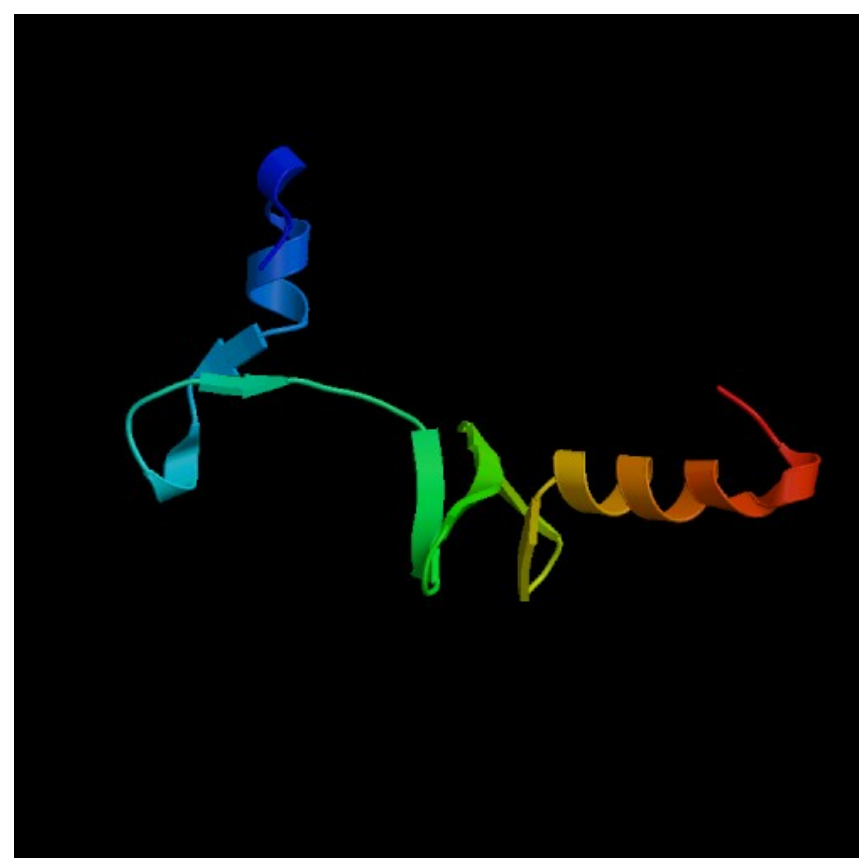

Fig 4. Genebank Accession No. AED87020.1

CONCLUSION

These in-silico studies for validation of some functionally important proteins of Microsystis aerogenosa (LNSAMB) were carried out for verifying the authenticity of the sequenced gene products. Bioinformatics Web Tools have shown the ability to predict structure and functions in such proteins.

\section{GENEBANK ACCESSION NUMBERS}

The Genebank accession numbers for submitted microcystin synthetase sequences are AED87017.1, AED87018.1, AED87019.1 and AED87020.1; whereas the accession numbers of the 16S rRNA gene sequence for the isolated Microsystis aerogenosa (LNSAMB) is HQ419176.

\section{ACKNOWLEDGEMENT}

We are thankful to Dr. Mrs. Lalita N. Sangolkar, Senior Scientist and Ms. Komal Y. Chambhare, Technical Assistant from Ecosystem Division, National Environmental Engineering Research Institute (NEERI), Nehru Marg, Nagpur-440020, Maharashtra (India).

\section{REFERENCES}

1. Alex, B., Lachlan, C., Richard, D., Robert, D. F., Volker, H., Sam, G.J., Ajay, K., Mhairi, M., Simon, M., Erik, L. L. S., David, J. S., Corin Y., Sean, R. E. The Pfam 
families' database. Nucleic Acids Research, Vol. 32, D138D141, 2004.

2. Altschul, S., F., Madden, T., L., Schaffer, A., A., Zhang, J., Zhang, Z., Miller, W., Lipman, D., J. Gapped BLAST and PSI-BLAST: a new generation of protein database search programs. Nucleic Acids Res. 25 (17), 3389402, 1997.

3. Aron, M. Bauer., John, B. A., Myra, K. D., Carol, D. S., Noreen, R. G., Marc, G., Luning, H., Siqian, H., David, I. H., John, D. J., Zhaoxi, K., Dmitri, K., Christopher, J. L.,Cynthia A. L., Chunlei, L., Fu, L., Shennan, L., Gabriele, H. M., Mikhail, M., James, S. S., Narmada, T., Roxanne, A. Y., Jodie, J. Y., Dachuan, Z., Stephen, H. B. CDD: a conserved domain database for interactive domain family analysis. Nucleic Acids Research, Vol. 35, D237-D240, 2006.

4. Cédric, N., Desmond, G. H., Jaap, H. T-coffee: a novel method for fast and accurate multiple sequence alignment. J. Mol. Biol. 302, 205-217, 2000.

5. Chih-Chieh, C., Jenn-Kang, H., Jinn-Moon, Y. (PS $)^{2}$ : protein structure prediction server Nucl. Acids Res. 34, W152-W157, 2006.

6. Dittmann, E., Neilan, B.A., Erhard, M., von Döhren, H., and Börner, T. (1997) Insertional mutagenesis of a peptide synthetase gene that is responsible for hepatotoxin production in the cyanobacterium Microcystis aeruginosa PCC 7806. Mol Microbiol 26: 779-787.

7. Edward, E., Gary, L. G., Osnat, H., John, M., John, O., Roberto, J. P., Linda, B., Delwood, R., Andrew, J. H. Biological function made crystal clear- annotation of hypothetical proteins via structural genomics. Current Opinion in Biotechnology 11, 25-30, 2000.

8. Kaebernick, M., Rohrlack, T., Christoffersen, K., and Neilan, B.A. (2001) A spontaneous mutant of microcystin biosynthesis: genetic characterization and effect on Daphnia. Environ Microbiol 3: 669-679.

9. Kurmayer, R., Dittmann, E., Fastner, J., and Chorus, I. (2002) Diversity of microcystin genes within a population of the toxic cyanobacterium Microcystis spp. in Lake Wannsee (Berlin, Germany). Microb Ecol 43: 107-118.

10. Mikalsen, B., Boison, G., Skulberg, O.M., Fastner, J., Davies, W., Gabrielsen, T.M., et al. (2003) Natural variation in the microcystin synthetase operon mcyABC and impact on microcystin production in Microcystis strains. J Bacteriol 185: $2774-2785$.

11. Nishizawa, T., A. Ueda, M. Asayama, K. Fujii, K. Harada, K. Ochi, and M. Shirai. 2000. Polyketide synthase gene coupled to the peptide synthetase module involved in the biosynthesis of the cyclic heptapeptide microcystin. J. Biochem. 127:779-789.

12. Nishizawa, T., Asayama, M., Fujii, K., Harada, K., and Shirai, M. (1999) Genetic analysis of the peptide synthetase genes for a cyclic heptapeptide microcystin in Microcystis spp. J Biochem 126: 520-529.

13. Roman, L. T., Michael, Y., Galperin, Darren A. Natale, Eugene V. Koonin. The COG database: a tool for genome scale analysis of protein functions and evolution. Nucleic Acid Research. 28, 33-36, 2000.

14. Schaffer, A. A., Aravind, L., Madden, T. L., Shavirin, S. Spouge, J. L., Wolf, Y. I., Koonin, E. V., Altschul, S. F. Improving the accuracy of PSI-BLAST protein database searches with composition-based statistics and other refinements. Nucleic Acids Res. 29(14), 2994-3005, 2001.

15. Tillett, D., E. Dittmann, M. Erhard, H. von Do“hren, T. Börner, and B. A. Neilan. 2000. Structural organization of microcystin biosynthesis in Microcystis aeruginosa PCC7806: an integrated peptide-polyketide synthetase system. Chem. Biol. 7:753-764.

16. Tillett, D., Parker, D.L., and Neilan, B.A. (2001) Detection of toxigenicity by a probe for the microcystin synthetase A gene (mcyA) of the cyanobacterial genus Microcystis: comparison of toxicities with $16 \mathrm{~S}$ rRNA and phycocyanin operon (phycocyanin intergenic spacer) phylogenies. Appl Environ Microbiol 67: 2810-2818. 
17. Wendy, B. et al. The EMBL Nucleotide Sequence Database. Nucleic Acid Research. 28, 19-23, 2000.

18. Zafer, A., Yucel, A., Mark, B. Protein secondary structure prediction for a single-sequence using hidden semiMarkov models, BMC Bioinformatics ,7, 178, 2006.

19. Zdobnov, E. M., Rolf, A. Interproscan- an integration platform for the signatures recognition methods in InterPro. Bioinformatics 17,847-848, 2001. 